\title{
Diagnostic value of cone beam computed tomography for recognition of oblique root fractures: An in vitro study
}

\section{Wartość diagnostyczna tomografii komputerowej wiązki stożkowej w rozpoznawaniu skośnych złamań korzeni zębów - badania in vitro}

\author{
Oskar Armata ${ }^{A-D, F}$, Elżbieta Bołtacz-Rzepkowska ${ }^{\mathrm{A}, \mathrm{E}, \mathrm{F}}$ \\ Department of Conservative Dentistry, Medical University of Lodz, Poland \\ A - research concept and design; $B$ - collection and/or assembly of data; $C$ - data analysis and interpretation; \\ $D$ - writing the article; $E$ - critical revision of the article; $F$ - final approval of the article
}

Address for correspondence

Oskar Armata

E-mail: oskararmata@gmail.com

Funding sources

Grant No. 502-03/2-044-01/502-24-031.

Conflict of interest

None declared

Received on March 10, 2018

Reviewed on April 14, 2018

Accepted on May 21, 2018

\begin{abstract}
Background. Diagnosis of tooth root fractures is based on radiographic examination, which is not reliable in the case of oblique root fractures.

Objectives. The aim of the study was to evaluate the efficacy of cone beam computed tomography (CBCT) imaging of oblique root fractures.

Material and methods. Twenty-four bovine incisors were used in the study. They were randomly divided into 2 groups: an experimental group with artificially created oblique root fractures and a control group without fractures. The teeth underwent a CBCT evaluation with a CS 9300 cone-beam scanner (Carestream, Rochester, USA) using a $5 \times 5 \mathrm{~cm}$ field of view with the resolution up to $90 \mu \mathrm{m}$, and a dental radiography. The specimens were examined by 2 observers with different job experience.

Results. In the CBCT scans, fracture lines were detected in 95.8\% of cases (the $1^{\text {st }}$ observer made a proper diagnosis in $100 \%$ of cases and the $2^{\text {nd }}$ in $91.7 \%$ ). Fracture lines were identified on radiographs in $33.3 \%$ of roots (the $1^{1 \mathrm{st}}$ observer was able to see the lines in $41.7 \%$ of cases and the $2^{\text {nd }}$ in $25 \%$ ). The inter-observer agreement was very high (the kappa coefficient for CBCT scans was 1.00 and 0.88 for radiographs). The best diagnostic value was recorded for contiguous slices.

Conclusions. Cone beam computed tomography with a small field of view and high resolution significantly surpasses radiographs in effective imaging of oblique tooth root fractures and should be the method of choice in the diagnosis of these fractures.
\end{abstract}

Key words: cone beam computed tomography, dental root fracture, diagnosis

Słowa kluczowe: tomografia komputerowa wiązki stożkowej, skośne złamanie korzenia, diagnostyka

DOI

10.17219/dmp/91405

Copyright

() 2018 by Wroclaw Medical University

and Polish Dental Society

This is an article distributed under the terms of the

Creative Commons Attribution Non-Commercial License

(http://creativecommons.org/licenses/by-nc-nd/4.0/) 
In recent years, tooth trauma has been frequently a cause of patients reporting to the dental office. ${ }^{1}$ Traumatic injuries to anterior teeth usually result in horizontal or oblique tooth root fractures. ${ }^{2,3}$ Jayasudha et al. evaluated different dynamic forces acting on the tooth during the injury using a three dimensional (3D) experimental model. ${ }^{4}$ Researchers stated that the greatest stresses in the dental and the alveolar bone tissues are induced by horizontal forces, leading to oblique fractures in the cervical or radicular region of the tooth. Another cause of oblique root fractures is repeated excessive pressure during the mastication of hard food, ${ }^{5,6}$ which is usually observed in subjects above the age of 40 years and mostly affects lateral teeth, resulting from age-related changes in tooth elasticity and the presence of numerous and large fillings. ${ }^{7}$

There is a lack of data on the prevalence of oblique root fractures, because they are frequently recognized as horizontal ones. The diagnosis of tooth root fractures is predominantly based on radiological imaging, which is often unreliable in relation to oblique fractures. The central ray of the X-ray beam, despite taking images at different angles (3 or more projections), does not always pass through the fracture fissure running obliquely to the long axis of the tooth. In addition, the fracture, which is recognized in the cervical third of the root on an X-ray taken with the use of the right angle technique, is visible at a different height on an occlusal or oblique radiograph. ${ }^{8}$

Improper recognition of the course of the fracture fissure is a cause of frequent therapeutic failures. Therefore, the study on the diagnostic possibilities of CBCT in identifying oblique root fractures is justifiable.

The aim of the study was to evaluate the efficacy of imaging oblique root fractures of teeth by using cone beam computed tomography (CBCT).

\section{Material and methods}

Twenty-four bovine lateral incisors of the mandible (the animals aged up to 36 months) were obtained from a slaughterhouse. After extraction, the teeth were cleansed from periodontal tissues and stored in $0.5 \%$ thymol solution at room temperature for maximally 2 months. The teeth were assessed under a microscope in order to eliminate roots with cracks. The pulp was extirpated according to the guidelines of the International Organization for Standardization. ${ }^{9}$

After cutting off the crowns below the cemento-enamel junction, the roots were randomly divided into 2 groups, experimental (A) and control (B). In group $\mathrm{A}$, an oblique fracture was generated in each root by using a universal testing machine Zwick/Roell Z020 (Zwick GmbH \& Co. KG, Ulm, Germany), with 3-point flexure (Fig. 1). Two parts of each tooth were pieced together and tightly glued with a universal scotch gel. In this way, the fracture fis-

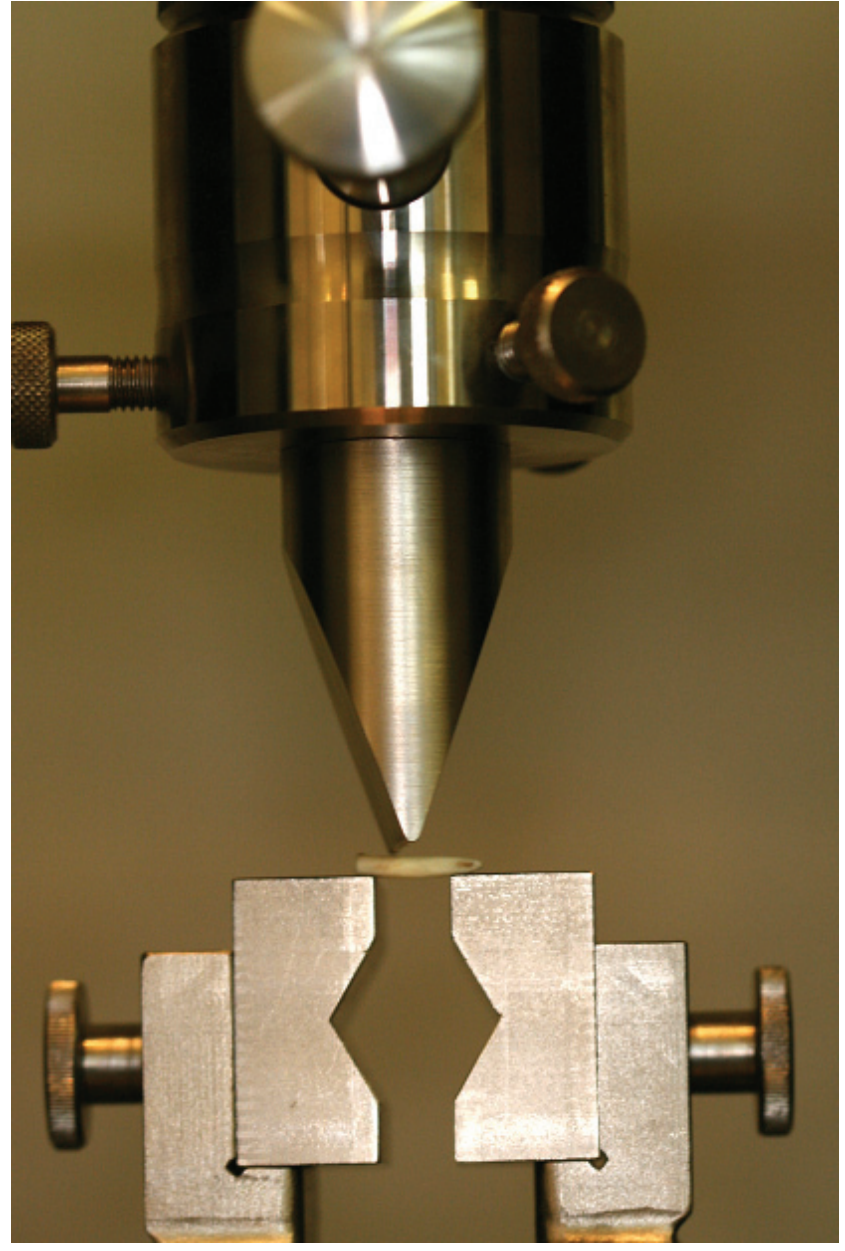

Fig. 1. Generating oblique fractures by using a universal testing machine Zwick/Roell Z020

sure width less than $0.1 \mathrm{~mm}$ was obtained in all fractures. The fissure width was evaluated with an electronic caliper (TESA Caliper IP67, 150 mm; TESA Technology, Renens, Switzerland) whose measurement accuracy was $0.01 \mathrm{~mm}$, confirmed by the calibration certificate No. AP302.1/12. The certificate was issued by the Mikro Pomiar calibration laboratory accredited by the Polish Centre for Accreditation. The measurements were performed centrally to the long axis of the tooth in relation to 2 constant reference points. Group B (control) consisted of the roots without fractures. The investigations were carried out in the University Laboratory of Material Research of the Medical University of Lodz (Poland). The teeth of both groups underwent radiographic and $\mathrm{CBCT}$ examination.

\section{Positioning of samples}

The roots of the studied teeth were covered with a layer of wax to simulate the periodontal ligament space. Next, they were placed in the alveoli of the human mandible and tightly adhered to the alveolar walls (Fig. 2). The vestibular and lingual aspects of the mandibular body were covered with 3 layers of modelling wax, each one $1.6 \mathrm{~mm}$ thick, which simulated soft tissues. 


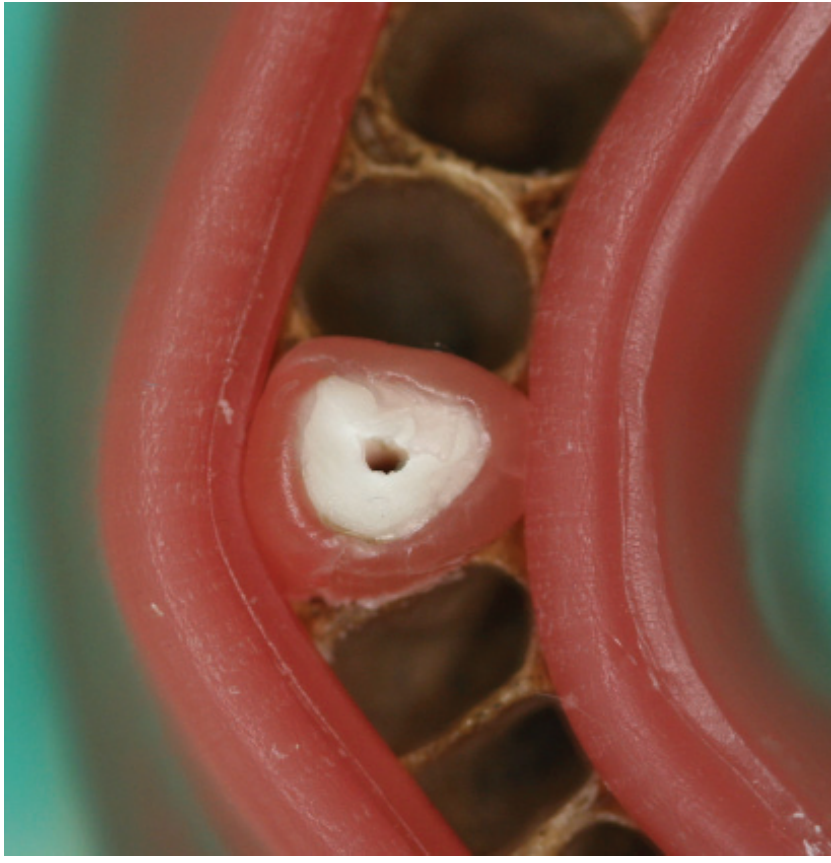

Fig. 2. A study model - human mandible with the dental root placed in the alveolus

\section{Volumetric scanning}

The samples were scanned with computed tomography CS 9300 Carestream ${ }^{\circledR}$ (Carestream, Rochester, USA) and a variable field of view. The mandible was placed in the center of the CT scan range, according to the $\mathrm{X}, \mathrm{Y}, \mathrm{Z}$ lines, which ensured repeatability of visualization conditions. The universal field of view $(5 \times 5 \mathrm{~cm})$ with the $90 \mu \mathrm{m}$ resolution was used in the study. Volumetric data was saved in the DICOM 3 format, and the images were analyzed using a compatible CS 3D Imaging Software (Carestream). The assessment was performed in axial, sagittal, frontal, transsectional and contiguous slices. Translucency was considered to be the fracture fissure when its borders did not exceed the outline of the tooth and were visible at least on 2 consecutive slices. ${ }^{10}$

\section{Radiographs}

Digital radiographs of both groups were taken with the Kodak 2200 Intraoral X-ray System + Kodak RVG 5100 Digital Radiography System (Carestream), which operates at a fixed distance of $25 \mathrm{~cm}$ between the radiation source and a detector. The CCD sensor was placed in the $\mathrm{X}$-ray image positioner, which enabled the researchers to maintain exposure reproducibility (Fig. 3). The images were analyzed using the compatible Kodak Dental Imaging System Software. Translucency was considered to be a fracture fissure when its borders did not exceed the outline of the tooth.

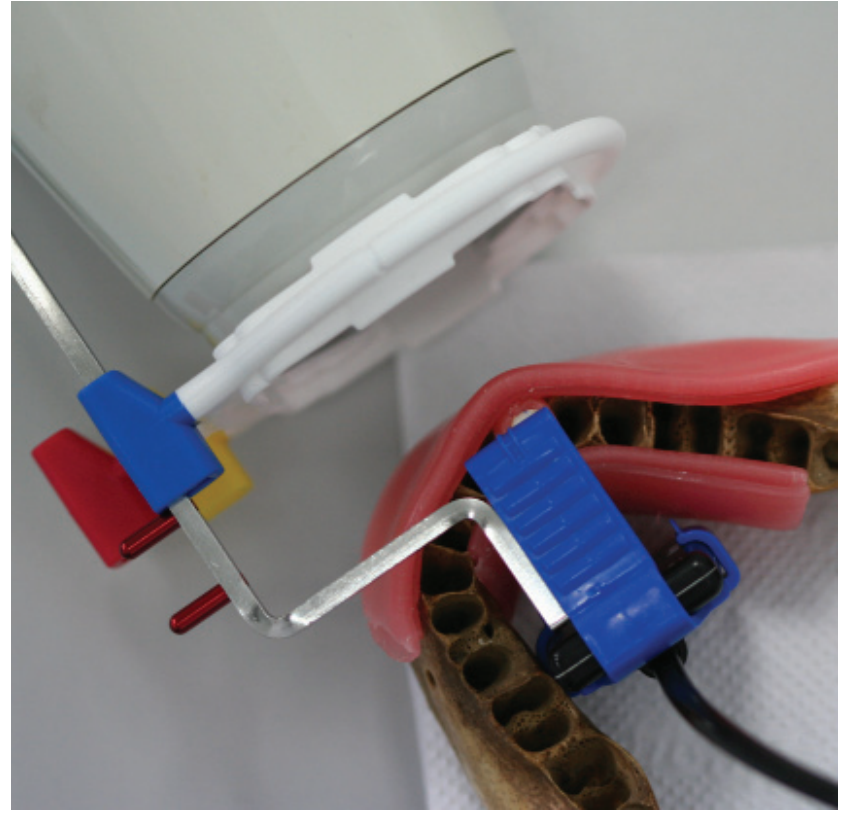

Fig. 3. Kodak 2200 Intraoral X-ray System with study model and the CCD sensor placed in the $\mathrm{X}$-ray image positioner

\section{Evaluation of radiographs}

$\mathrm{X}$-rays and CBCT scans were evaluated according to the 2 -grade scale where: - was invisible fracture and + was visible fracture.

The evaluation was performed by 2 observers who differed in the time of professional work experience (observer I had been working as a dentist for 5 years and observer II for 30 years). They used a 19-inch LCD monitor (NEC MultiSync EA192M, USA; resolution $1280 \times 1024$ ). The time of evaluation was not limited. The inter-observer agreement was expressed by means of the kappa coefficient, ${ }^{11}$ in which the value $<0.10$ shows a lack of agreement; $0.11-0.20$ a very low level of agreement; $0.21-0.40$ low; $0.41-0.60$ moderate; $0.61-0.80$ high; and $0.81-1.00$ a very high level of agreement.

In the statistical analysis of the study results, the $\chi^{2}$ test of independence and the Fisher's exact test (depending on the expected cell counts in the contingency tables) were used to compare the frequency of visualization of fracture fissures. ${ }^{12}$ The following measures were used to evaluate the research methods: sensitivity, specificity, and accuracy. Sensitivity describes which percentage of fractured teeth is detected by means of a given method, specificity shows which percentage of teeth without fractures is properly diagnosed, and accuracy presents the probability of a correct diagnosis using a given method (the extent to which a researcher can be certain that the obtained result is true).

The level of significance for the applied tests was set at $\alpha=0.05$. The statistical analysis was performed using STATISTICA v. 12 PL (StatSoft, Tulsa, USA).

The similar above-mentioned methodology was used in the author's previous publications. ${ }^{13-15}$ 


\section{Results}

Table 1 presents a comparison of the prevalence of fracture fissure identification by means of $\mathrm{CBCT}$ and radiographs in the teeth with and without fracture (control group) (Fig. 4, 5). The $1^{\text {st }}$ observer established the correct diagnosis in all evaluated cases in the CBCT study, while the $2^{\text {nd }}$ one in $91.7 \%$. Fracture fissures in the teeth with generated oblique fractures were visible in $95.8 \%$ of the CBCT scans. Both observers correctly recognized the fracture fissure in $33.3 \%$ of the dental roots on the radiographs; the $1^{\text {st }}$ researcher found fractures in $41.7 \%$ of the cases and the $2^{\text {nd }}$ one in $25 \%$. In the control group (B), both observers made the correct diagnoses in all examined cases, both in $\mathrm{CBCT}$ and radiographic examinations.

Table 1. Frequency of fracture fissure detection for CBCT scans and radiographs in the teeth with oblique fractures and in controls

\begin{tabular}{|l|c|c|c|}
\hline \multicolumn{1}{|c|}{ Group } & $\begin{array}{c}\text { CBCT - correct } \\
\text { diagnoses, } \\
n(\%)\end{array}$ & $\begin{array}{c}\text { RTG - correct } \\
\text { diagnoses, } \\
n(\%)\end{array}$ & $p$-value \\
\hline $\begin{array}{l}\text { A - oblique fractures } \\
\text { (observer I) }\end{array}$ & $12(100)$ & $5(41.7)$ & 0.016 \\
$\begin{array}{l}\text { A - oblique fractures } \\
\text { (observer II) }\end{array}$ & $11(91.7)$ & $3(25)$ & 0.008 \\
$\begin{array}{l}\text { A - total } \\
\text { B- control }\end{array}$ & $23(95.8)$ & $8(33.3)$ & 0 \\
\hline
\end{tabular}

CBCT - cone beam computed tomography.

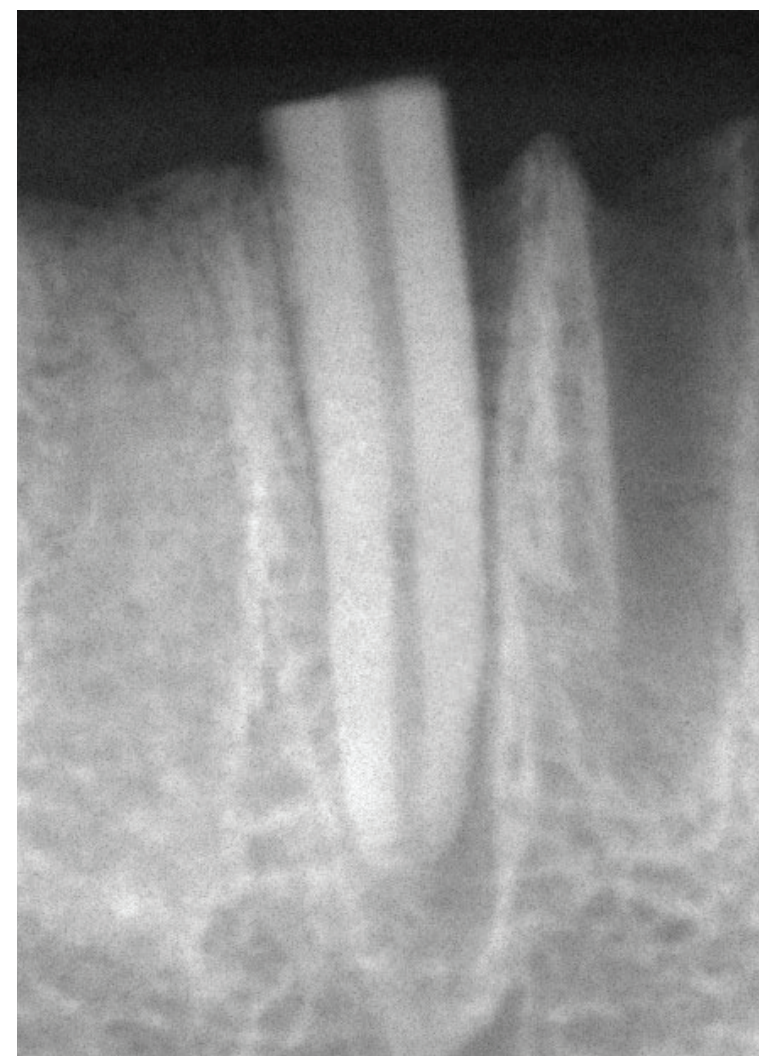

Fig. 4A. X-ray of tooth No. 2 - fracture not visible

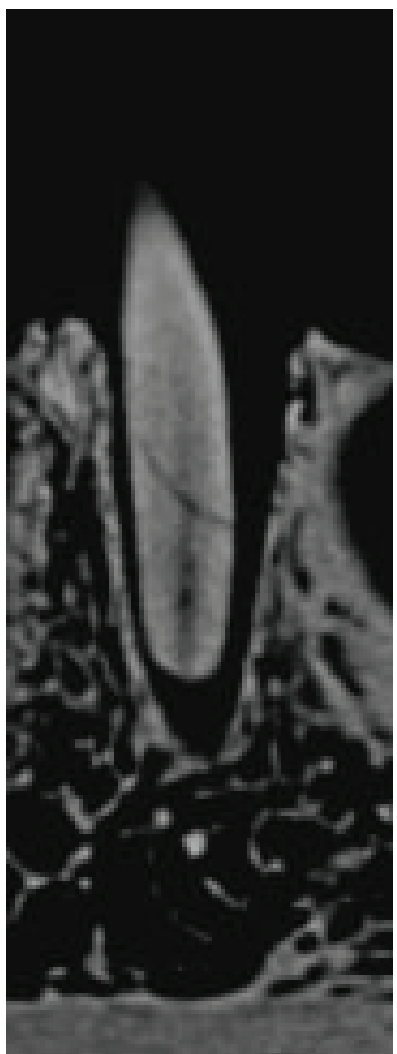

Fig. 4B. Contiguous slice of tooth No. 2 - fracture visible

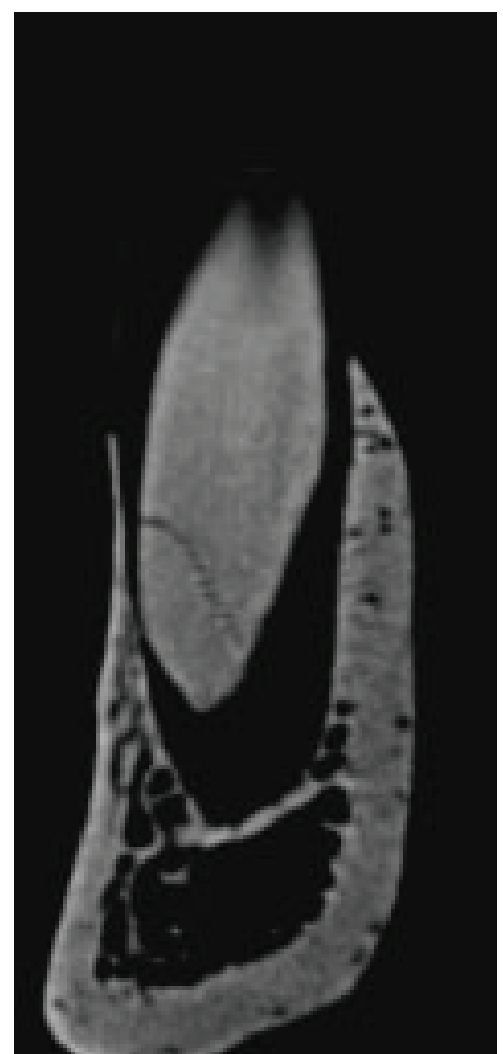

Fig. 4C. Transsectional slice of tooth No. 2 - fracture visible
As can be seen from the data in Table 1, the frequency of correct detection of oblique tooth root fractures for the CBCT scans was statistically significantly higher than for the radiographs $(\mathrm{p}<0.05)$. This correlation denoted the presence of statistically significant differences in the sensitivity, specificity and accuracy used to describe the evaluated radiological methods in further analysis (Table 2). These differences can occur in all parameters or only in some of them.

The sensitivity, as described above, was $95.8 \%$ for CBCT scans and $33.3 \%$ for radiographs. The specificity reached the same $100 \%$ value in both diagnostic methods. The diagnostic accuracy for radiographs (66.7\%) was lower than in the CBCT evaluation (97.9\%) (Table 2).

Table 3 presents the diagnostic value of particular CBCT slices in the detection of the oblique root fractures. The data shows that the best diagnostic value was obtained for the contiguous slices.

The evaluation of the inter-observer agreement expressed by the kappa coefficient for the CBCT and radiographic evaluation is presented in Table 4. The kappa coefficient for the teeth with oblique fractures was 0.70 in the X-ray examination and 0.92 in relation to $\mathrm{CBCT}$ scans. The inter-observer agreement was, therefore, very high for the volumetric tomography studies and high for radiographs (Table 4). 


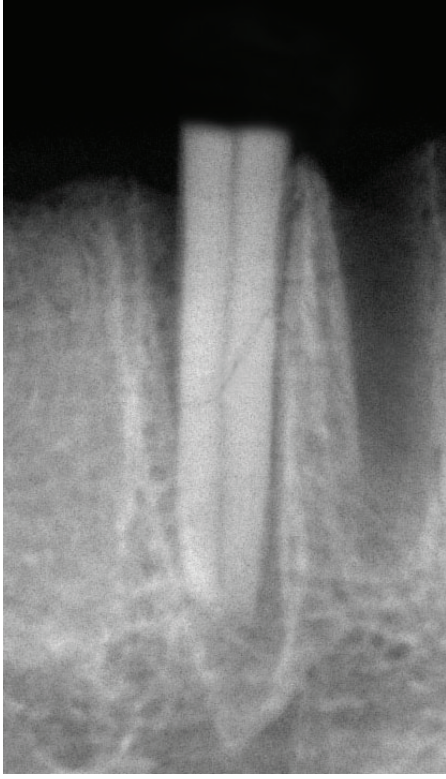

Fig. 5A. X-ray of tooth No. 12 - fracture visible

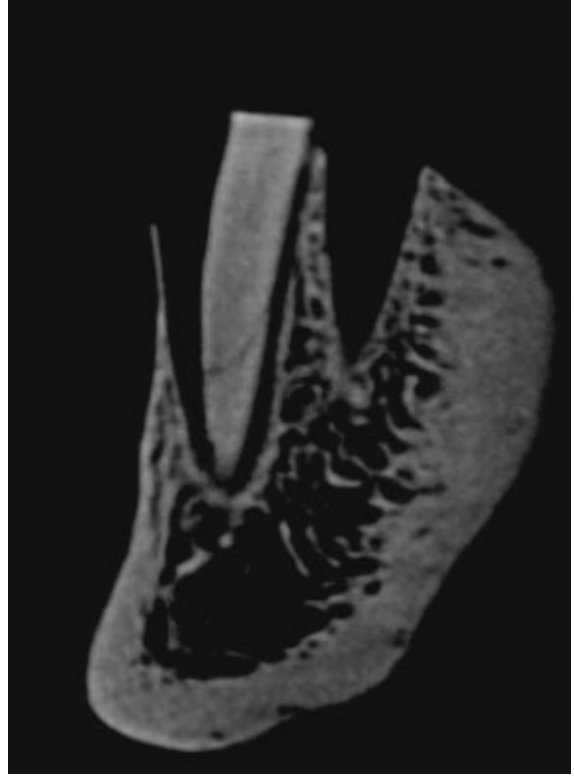

Fig. 5B. Sagittal slice of tooth No. 12 - fracture visible

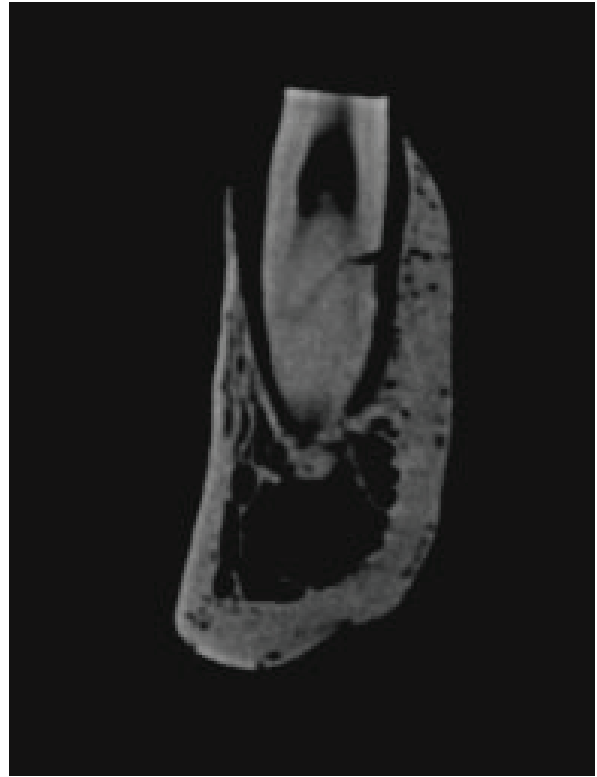

Fig. 5C. Transsectional slice of tooth No. 12 - fracture visible

Table 2. Sensitivity, specificity and accuracy for CBCT scans and radiographs in the detection of oblique root fractures according to the observer

\begin{tabular}{|l|c|c|cc|c|c|}
\hline \multicolumn{1}{c|}{ Test } & Total CBCT scans & CBCT 1 & CBCT 2 & Total radiographs & RTG 1 & RTG 2 \\
\hline Sensitivity & $95.80 \%$ & $100.00 \%$ & $91.70 \%$ & $33.30 \%$ & $1.70 \%$ \\
Specificity & $100.00 \%$ & $100.00 \%$ & $100.00 \%$ & $100.00 \%$ & $100.00 \%$ \\
Accuracy & $97.90 \%$ & $100.00 \%$ & $95.80 \%$ & $66.70 \%$ & $70.80 \%$ \\
\hline
\end{tabular}

CBCT - cone beam computed tomography.

Table 3. Diagnostic value of particular CBCT slices in the detection of oblique root fractures

\begin{tabular}{|c|c|c|cc|c|}
\multicolumn{1}{c|}{ Test } & CBCT - total & Axial & Frontal & Sagittal & Transsectional \\
\hline Sensitivity & $95.80 \%$ & $83.30 \%$ & $91.70 \%$ & $95.80 \%$ & $91.70 \%$ \\
Specificity & $100.00 \%$ & $100.00 \%$ & $100.00 \%$ & $100.00 \%$ & $100.00 \%$ \\
Accuracy & $97.90 \%$ & $91.70 \%$ & $95.80 \%$ & $97.90 \%$ & $100.00 \%$ \\
\hline
\end{tabular}

CBCT - cone beam computed tomography.

Table 4. The inter-observer agreement for the CBCT and radiographic study in the detection of oblique root fractures

\begin{tabular}{|l|c|c|c|c|c|}
\multicolumn{1}{|c|}{ Method } & Sample & $\begin{array}{c}\text { Kappa } \\
\text { coefficient }\end{array}$ & Error & $\begin{array}{c}\text { Test } \\
\text { statistics }\end{array}$ & p-value \\
\hline CBCT & oblique & 0.92 & 0.08 & 4.51 & 0 \\
Radiographs & oblique & 0.7 & 0.19 & 3.61 & 0 \\
\hline
\end{tabular}

CBCT - cone beam computed tomography.

\section{Discussion}

The subject of diagnosing oblique dental root fractures has been rarely undertaken in literature and concerned monitoring of post-traumatic tooth injuries. ${ }^{16-18}$ In the literature, there is only one available in vitro study performed by Iikubo et al., in which the authors evaluated oblique root fractures using 2 types of dental radiographs (right angle and bisecting angle technique; apparatus DX-1, GC Co., Tokyo, Japan) and CBCT (CB
Throne tomography, Hitachi Medical Corp., Tokyo, Japan, $10 \times 10 \mathrm{~cm}$ field of view, with a resolution of 200 $\mu \mathrm{m}) .{ }^{19}$ Human central incisors were used in the experiment. The roots were divided into 3 groups: in the $1^{\text {st }}$ one, transverse fractures at an angle of $90^{\circ}$ to the long axis of the tooth were generated, in the $2^{\text {nd }}$ and $3^{\text {rd }}$ one, fractures at $75^{\circ}$ and $55^{\circ}$ were induced. Roots were cut with abrasive discs of various thicknesses $(0.15 \mathrm{~mm}$, $0.25 \mathrm{~mm}, 0.35 \mathrm{~mm}$ ) at appropriate angles until the root canal was reached. The roots were not broken and glued together as in our study, thus to compare the outcomes of both studies, we selected the group of roots with the smallest groove width of $0.15 \mathrm{~mm}$, which was closest to the fissure width evaluated in our experiment. Iikubo et al. noticed that grooves performed at an angle of $75^{\circ}$ were poorly visible on radiographs taken with the bisecting angle technique. ${ }^{19}$ The same situation occurred on radiographs taken with the right angle technique, where radiographs taken at an angle of $55^{\circ}$ were not 
well visualized. According to the authors, the results clearly indicate difficulties in diagnosing such fractures using $\mathrm{X}$-ray images.

In compliance with the studies of citied authors, ${ }^{19}$ the sensitivity for $\mathrm{CBCT}$ scans in the detection of fractures at an angle of $75^{\circ}$ was $94 \%$ as compared to $75 \%$ for radiographs taken with the paralleling technique and 12\% for the Cieszynski's rule of isometry technique. For fractures induced at an angle of $55^{\circ}$, the volumetric evaluation showed a sensitivity of $96 \%$, and a radiographic examination presented a sensitivity of $13 \%$ and $98 \%$, respectively. The results from the mentioned data indicated that the cone beam CT appeared to be the most efficient modality for detecting the discussed fractures. Moreover, as regards radiographs, it should be added that the closer the angle of incidence of the radiation beam to the plane of fracture occurred, the better the fracture fissure was shown. This finding is in line with other literature reports. ${ }^{20,21}$

In the present study, the sensitivity of CBCT scans was $95.8 \%$, whereas that of the radiographs taken in the right angle technique was $33.3 \%$. Therefore, it can be concluded that the angle of incidence of the central ray in the paralleling technique while taking radiographs was close to the plane of the course of the fracture fissure only in $1 / 3$ of the cases.

Specificity was a subsequent studied parameter. Iikubo et al. did not record any statistically significant differences in the values of this indicator for the evaluated radiological methods (100\% CBCT, 96\% right angle technique, $82 \%$ bisecting angle technique). ${ }^{19}$ We did not observe differences in the specificity in our study either. In both methods used, the discussed parameter was 100\%.

Among the slices used for the evaluation of fractures, the contiguous one appeared to be most efficient. There are no publications on this subject in the available literature; therefore, this parameter cannot be compared with the findings of other authors.

Iikubo et al. also presented the aspect of inter-observer agreement. ${ }^{19}$ The evaluation was performed by 7 radiologists with more than 10 -year professional work linked into pairs (21 pairs). After calculating the kappa coefficient for particular radiological methods, the highest value was found for volumetric tomography (0.83), followed by the paralleling technique (0.68) and the Cieszynski's rule of isometry (0.51). It can be observed that the results of our study are similar -0.92 for $\mathrm{CBCT}$ and 0.70 for radiographs with the use of the right angle technique.

Clinical implications of the present study are worth emphasizing. As can be concluded from literature reports, ${ }^{16-18}$ despite different projections of radiographs, oblique root fractures are frequently identified as horizontal ones. Bornstein et al. evaluated 44 cases of fractures, which were diagnosed on the basis of radiographs as horizontal root fractures. ${ }^{18}$ The examination of volumetric scans demonstrated that $68.2 \%$ of them had an oblique course of the fracture fissure. Additionally, a fracture, which on a conventional radiograph was located in the middle or apical third of the root, on sagittal slices from palatal aspects is extended towards the tooth cervix.

Moreover, the authors noticed that the image of the horizontal fracture observable on the radiographs and CBCT scans from the vestibular aspect indicated a similar location of the fissure in $70.5 \%$ of the cases contrary to radiographs and scans taken from the palatal aspect, which confirmed the location of the fissure in only $31.8 \%$ of the cases.

In the clinical setting, artifacts may occur during the diagnosis of dental root fractures with the use of CBCT. They derive from radiopaque materials, such as gutta-percha and sealers used during root canal filling, metals from prosthetic appliances or are associated with the patient's movement during CBCT scanning. Image distortions in the form of star-shaped streaks imitating fracture gaps may affect the diagnostic value of CBCT examinations. ${ }^{22-24}$

However, it should be emphasized that the software in CBCT examinations allows dental practitioners to view teeth in at least 5 slices and different planes as well as from many angles. The fracture visible on 5, 4, 3 or even 2 slices of a particular scan enables clinicians to make a proper diagnosis.

The proper location of the fissure in the tooth with horizontal fracture allows dental practitioners to undertake adequate therapeutic management, i.e. root canal treatment or apicectomy. Idiopathic healing is also possible. Oblique root fracture is usually an indication that a tooth extraction is necessary. Treatment of such a fracture is always associated with failure, additionally leading to the loss of the alveolar bone, which makes further implant therapy more difficult.

\section{Conclusions}

The study indicated that $\mathrm{CBCT}$ is an effective method in diagnosing oblique dental root fractures. A contiguous slice appeared to be most effective in imaging oblique root fractures. The observer's experience did not play a significant role in the detection of oblique root fractures by means of CBCT.

\section{References}

1. Robertson A, Noren JG. Knowledge-based system for structured examination, diagnosis and therapy in treatment of traumatised teeth. Dent Traumatol. 2001;17:5-9.

2. Glendor U. Epidemiology of traumatic dental injuries a 12 year review of the literature. Dent Traumatol. 2008;24:603-611.

3. Andreasen JO, Andreasen FM, Andersson I. Classification, etiology and epidemiology. In: Textbook and Color Atlas of Traumatic Injuries to the Teeth. $4^{\text {th }}$ ed. Mosby, MO: Mosby Inc; 2007;217-244.

4. Jayasudha K. Traumatic impact loading on human maxillary incisor: A Dynamic finite element analysis. J Indian Soc Pedodont Prevent Dent. 2015;33(Suppl 4):302-306.

5. Yang SF, Rivera EM, Walton RE. Vertical root fracture in nonendodontically treated teeth. J Endod. 1995;21:337-339. 
6. Yeh CJ. Fatigue root fracture: A spontaneous root fracture in nonendodontically treated teeth. Br Dent J. 1997;182:261-266.

7. Lin CC, Tsai YL, Li UM, Chang YC, Lin CP, Jeng JH. Horizontal/oblique root fractures in the palatal root of maxillary molars with associated periodontal destruction: Case reports. Int Endod J. 2008;41:442-447.

8. May JJ, Cohenca N, Peters OA. Contemporary management of horizontal root fractures to the permanent dentition: Diagnosis-radiologic assessment to include cone-beam computed tomography. Pediatr Dent. 2013;35:120-124.

9. Technical Specification ISO/TS 11405, Dental materials - Testing of adhesion to tooth structure.

10. Różyło-Kalinowska I, Różyło TK. Cone-beam computed tomography in diagnostics of vertical dental root fracture - in vitro study [in Polish]. Czas Stomatol. 2010;63:191-198.

11. Cohen J. A coefficient of agreement for nominal scales. Educational and Psychological Measurement. 1960;10:37-46.

12. Woolson RF. Statistical Methods for the Analysis of Biomedical Data. New York, NY: John Wiley \& Sons, Inc.; 1987;204-238.

13. Armata O, Bołtacz-Rzepkowska E. Use of cone-beam computed tomography scans in diagnose of vertical root fractures in endodontically treated teeth. An in vitro study [in Polish]. Magazyn Stomatol. 2014;24:5:84-89.

14. Armata O, Bołtacz-Rzepkowska E. Diagnostic value of cone-beam computed tomography in diagnosing vertical root fractures in endodontically treated teeth - an in vitro study. J Stoma. 2016;69:694-708.

15. Armata O, Bołtacz-Rzepkowska E. Diagnostic value of cone-beam computed tomography in diagnosing horizontal root fractures - an in vitro study [in Polish]. Magazyn Stomatol. 2017;27:5:40-46.

16. Cvek M, Andreasen JO, Borum MK. Healing of 208 intra-alveolar rootfractures in patients aged 7-17 years. Dent Traumatol. 2001;17:53-62.

17. Cvek M, Tsilingaridis G, Andreasen JO. Survival of 534 incisors after intra-alveolar root fracture in patients aged 7-17 years. Dent Traumatol. 2008;24:379-387.

18. Bornstein MM, Wölner-Hanssen AB, Sendi $P$, von Arx T. Comparison of intraoral radiography and limited cone beam computed tomography for the assessment of root-fractured permanent teeth. Dent Traumatol. 2009;25:571-577.

19. likubo M, Kamio T, Hashimoto $\mathrm{N}$, et al. Comparison of bisecting and parallel intraoral radiography and cone-beam computed tomography for detecting various horizontal angle root fractures. Oral Radiol. 2015;31:173-180.

20. Nair MK, Nair UP. Digital and advanced imaging in endodontics: A review. J Endod. 2007;33:1-6.

21. Degering $\mathrm{Cl}$. Radiography of dental fracture. An experimental evaluation. Oral Surg Oral Med Oral Pathol. 1970;30:213-219.

22. Wang $P$, Yan XB, Lui DG, et al. Detection of dental root fractures by using cone-beam computed tomography. Dentomaxillofac Radiol. 2011;40:290-298.

23. Melo SL, Bortoluzzi EA, Abreu M Jr, et al. Diagnostic ability of a conebeam computed tomography scan to assess longitudinal fractures in prosthetically treated teeth. J Endod. 2010;36:1879-1882.

24. Khedmat S, Rouhi N, Drage N, et al. Evaluation of three imaging techniques for the detection of vertical root fractures in the absence and presence of gutta-percha root fillings. Int Endod J. 2010;45:1004-1009. 
